\title{
Effect of Spinal Immobilization with a Long Backboard and Cervical Collar on the Vital Signs
}

Şeref Kerem Çorbacıoğlu, Şaban Akkuş, Yunsur Çevik, Emine Akıncı, Hüseyin Uzunosmanoğlu

Clinic of Emergency Medicine, Keçiören Training and Research Hospital, Ankara, Turkey

\begin{abstract}
Aim: The aim of this study was to research the effect of a long backboard (LBB) and cervical collar (CC) devices on neck and/or back pain and changes in the vital signs of healthy subjects.
\end{abstract}

Materials and Methods: This study was conducted in the emergency department of a training and research hospital with 45 healthy adult volunteers. All the volunteers were asked to lie down on the LBB, and a CC was applied. All the vital signs, including respiratory rate (RR), heart rate (HR), oxygen saturation $\left(\mathrm{SO}_{2}\right)$, blood pressure (BP) and visual analog scores (VAS) were measured and recorded for all the volunteers at 0,5, and $30 \mathrm{~min}$.

Results: Significant increases in VAS and significant decreases in systolic BP were detected ( $p$-values were $<0.001$ and 0.01 , respectively). However, in terms of diastolic $\mathrm{BP}, \mathrm{RR}, \mathrm{HR}$, and $\mathrm{SO}_{2}$, no significant changes were detected.

Conclusion: Physicians should be aware that spinal immobilization with LBB and CC can cause significant changes in some vital signs, such as SBP and VAS. However, data on this topic is limited; therefore, there is a need for further studies involving a larger cohort population. (Eurasian J Emerg Med 2016; 15: 65-8)

Keywords: Spinal immobilization, long backboard, cervical collar, vital signs, visual analog score

\section{Introduction}

Trauma is the leading cause of death among non-elderly individuals worldwide, and it has a high mortality and morbidity rate in general (1). Some major concerns related to trauma, particularly among emergency physicians, include the failure to manage spinal injuries and shock, especially hemorrhagic shock in multi-trauma patients. Therefore, immobilization of the spine and a close evaluation of the patient's vital signs during the management of trauma patients are crucial and routinely recommended, especially in blunt trauma patients (2). Close following of the vital signs is recommended by the Advanced Trauma Life Support guidelines for the diagnosis of hemorrhagic shock in the early stages. The vital signs can be affected by several parameters, such as pain, anxiety, medication, and spinal cord injury $(2,3)$.

Spinal immobilization is achieved using a long backboard (LBB) and a combination of rigid or semi-rigid cervical collar (CC) in most emergency medicine systems worldwide $(4,5)$. Although LBB and CC are commonly recommended by international guidelines for spinal immobilization of blunt trauma patients, evidence of the effectiveness of these devices is limited (6-8). In addition, several studies have shown that both devices may cause several side effects, such as pain, anxiety, increased intracranial pressure, decreased pulmonary function, and skin ulcers (9-11). However, to the best of our knowledge, the number of studies on the effects of spinal immobilization on vital signs is limited.

In this study, we aimed to research the effect of LBB and CC devices on neck and or back pain and changes in the vital signs of healthy subjects.

\section{Materials and Methods}

This study was conducted in the emergency department of a training and research hospital with 45 healthy adult volunteers. This study was approved by the local ethics committee of Keçiören Training and Research Hospital/B.10.4.ISM.4.06.68.49 and conducted over a 2-month period in 2015. Written informed consent was obtained from all subjects before procedures were performed.

Correspondence to: Şeref Kerem Çorbacıoğlu e-mail: serefkeremcorbacioglu@gmail.com 


\section{Volunteer population}

Forty-five healthy adult volunteers who had not taken any analgesic drugs within a period of at least $24 \mathrm{~h}$ were included in this study; volunteers were between 20 and 30 years of age, and the study included both male and female (non-pregnant) participants. Volunteers with a body mass index of $>30 \mathrm{~kg} / \mathrm{m}^{2}$, those experiencing pain of any kind, and those with medical conditions that prevent the application of LBB or CC were excluded. Before the study was conducted, all the volunteers underwent systemic physical examination. Volunteers who had an abnormal physical examination or vital sign findings were excluded from the study.

\section{Measurements and application of LBB and CC}

All the volunteers were asked to sleep for at least $8 \mathrm{~h}$ the night before the study and to fast for at least $2 \mathrm{~h}$ before the measurements of vital signs were taken. All the measurements were taken between 10 and 11 AM. After a 30-min resting period and a brief physical examination, all the volunteers were asked to lie down on the LBB, and a CC was applied to find the required size according to the volunteers (Figure 1). All the vital signs, including respiratory rate (RR), heart rate $(\mathrm{HR})$, oxygen saturation $\left(\mathrm{SO}_{2}\right)$, and blood pressure $(\mathrm{BP})$, were then measured for all the volunteers. All the vital signs, excluding RR, were measured by Nihon Kohden BSM- $2301 \mathrm{~K}^{\circ}$ on the right upper extremity of the volunteers and RR was measured manually by the physician. In addition, to evaluate pain related to the spinal immobilization, a visual analog score (VAS) was taken. The VAS ranged from 0 to 100, with 0 being "no pain" and 100 being "worst possible pain." All the measurements were taken at the beginning of the study and repeated during the $5^{\text {th }}$ and $30^{\text {th }}$ minutes of the study. If the patient reported side effects, they were recorded.

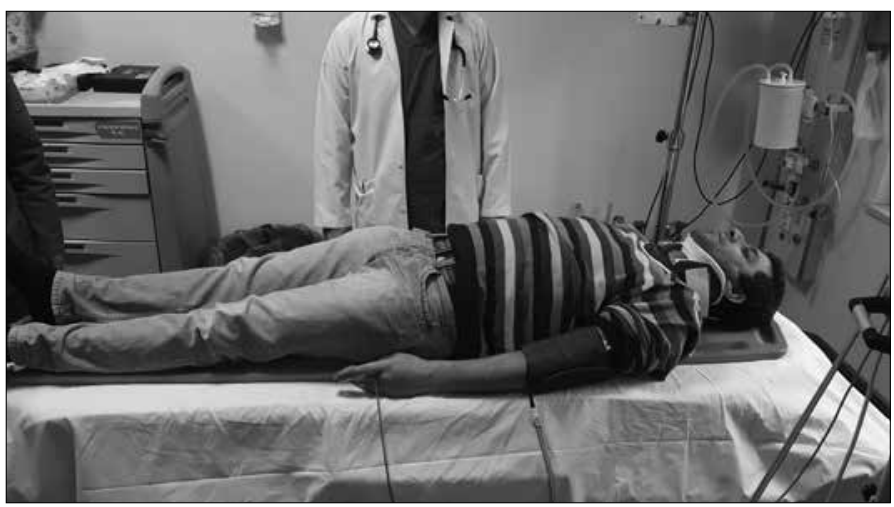

Figure 1. Applying a long backboard and cervical collar for spinal immobilization

\section{Statistical analyses}

Statistical analyses were performed using the Statistical Package for the Social Sciences 15.0 (SPSS Inc; Chicago, IL, USA). The Kolmogorov-Smirnov test was used to assess the normal distribution of all the parameters related to the volunteers. Non-parametric data of the volunteers were expressed as the number, percentage, median values, and inter-quartile-range (IQR) (25\%-75\%). Dependent non-parametric samples were analyzed by using Friedman and Wilcoxon tests. For more two-dependent group comparisons, Bonferroni correction was used. The $95 \%$ confidence intervals $(95 \% \mathrm{Cls}$ ) were also calculated whenever appropriate, and a p-value less than 0.05 was considered statistically significant.

\section{Results}

Of all the volunteers, 24 (53.5\%) were male and 21 (46.5\%) were female. The median age of the patients was 29 years (IQR: 26-30), the median weight was $70 \mathrm{~kg}$ (IQR: 61-79), and the median height was $168 \mathrm{~cm}$ (IQR: 164-175). The median systolic BP values of patients at minutes 0,5 , and 30 were $117 \mathrm{mmHg}$ (IQR: 110-131), $110 \mathrm{mmHg}$ (IQR: 105-120), and $110 \mathrm{mmHg}$ (IQR: 104-125), respectively. The median VAS values of patients at minutes 0,5 , and 30 were $0 \mathrm{~mm}$ (IQR: 0-0), $0 \mathrm{~mm}$ (IQR: 0-20), and $10 \mathrm{~mm}$ (IQR: 0-40), respectively. When the findings at minutes 0,5 , and 30 were compared in terms of systolic BP (SBP) and VAS, significant increases in VAS (this significant increasing was detected from minute 0 to minute 5 and from minute 5 to minute 30) and significant decreases in SBP (this significant decrease was detected only from minute 0 to minute 5) were detected, and the $p$-values of these differences were $<0.001$ and 0.01 , respectively (a new alpha level was calculated as 0.016 after the Bonferroni Correction). However, in terms of diastolic $\mathrm{BP}, \mathrm{RR}, \mathrm{HR}$, and $\mathrm{SO}_{2^{\prime}}$ no significant changes were detected. All the findings for the vital signs and VAS are shown in Table 1.

\section{Discussion}

In this study, we researched the effect of spinal immobilization through the use of CC and LBB on the vital signs as well as on neck and back pain. To the best of our knowledge, there is only one other study on the direct effect of spinal immobilization on vital signs. We believe that our study yielded two important results. First, spinal immobilization significantly increases neck and back pain, especially 30 min after application. Second, spinal immobilization significantly decreases SBP, and this decrease was detected 5 min after application. We believe that the second result is especially important because emergency physicians usually follow the vital signs (especially blood

Table 1. All vital signs and visual analog scores of volunteers at the $0^{\text {th }}, 5^{\text {th }}$, and $30^{\text {th }}$ min (median-IQR)

\begin{tabular}{|c|c|c|c|c|}
\hline & $\mathbf{0} \min$ & $5^{\text {th }} \min$ & $30^{\text {th }}$ min & p value \\
\hline Systolic blood pressure $(\mathrm{mmHg})$ & $117(110-131)$ & $110(105-120)$ & $110(104-125)$ & 0.01 \\
\hline Diastolic blood pressure (mmHg) & 70 (64-79) & $70(64-77)$ & $71(60-79)$ & 0.89 \\
\hline Breath rate (breath/min) & $20(18-24)$ & $20(17-24)$ & $20(18-24)$ & 0.56 \\
\hline Oxygen saturation (\%) & $96(95-97)$ & $96(95-97)$ & $96(95-97)$ & 0.66 \\
\hline
\end{tabular}


pressure) of patients with severe trauma to ensure an early diagnosis of hypovolemic shock. In two previous studies conducted by Guly et al. (12) on testing vital signs to estimate the stage of hypovolemic shock in trauma patients, SBP was reported to be $8-15 \mathrm{mmHg}$ lower in stage 4 shock patients than in stage 1 shock patients and SBP was 4-7 mmHg lower in stage 3 shock patients than in stage 1 shock patients (3). In our study, SBP decreased by nearly $7 \mathrm{mmHg}$ as a result of spinal immobilization. We believe that this decrease could be a confounding factor in the diagnosis and management of hemorrhagic shock in trauma patients. Of course, it is considered that our study utilized a very small and narrow age-limited population; thus, our results may not be enough to support precise judgments. However, we believe that physicians should be aware that spinal immobilization with LBB and CC can cause significant changes in SBP levels, especially in the first $5 \mathrm{~min}$.

Neck and/or back pain is the most commonly reported side effect of spinal immobilization with LBB and CC. Other side effects include anxiety, increased intracranial pressure, decreased pulmonary function, and skin ulcers $(13,14)$. Pain is not usually limited to regions of contact with LBB; spinal immobilization can also cause cervical spine or lower back pain due to the non-ergonomic position (7). In addition, these pains have been reported to persist for up to $24 \mathrm{~h}$ after only $1 \mathrm{~h}$ of LBB, and they can provoke unnecessary radiological exams $(9,15)$. In a previous study, Cordell et al. (16) reported that the use of LBB causes increased pain in the neck and lumbar areas. Another study conducted by Edlich et al. (17) reported that the VAS of volunteers increased nearly six-fold after $30 \mathrm{~min}$ of LBB use. We also found that VAS levels increased during the $5^{\text {th }}$ and $30^{\text {th }}$ minutes of LBB use. These two previous studies reported that using a mattress-attached spine board decreased the VAS of volunteers when compared to LBB without the use of a mattress. We believe that using a mattress with LBB can be effective for preventing pain related to LBB, especially if the patients need to lie down on the spine board for an extended period of time.

There have been several studies on the effects of spinal immobilization on pulmonary function, and these studies have shown that forced expiratory volume in $1 \mathrm{~s}\left(\mathrm{FEV}_{1}\right)$ and forced vital capacity (FVC) levels significantly decreased at the $5^{\text {th }}$ and $30^{\text {th }}$ minutes (18-20). In our study, secondary indicators of pulmonary function, breath rate, and oxygen saturation were also assessed, and it was shown that they were not affected by spinal immobilization. However, it should not be overlooked that our study population consisted of healthy volunteers. Therefore, if this study were repeated with patients suffering from pulmonary disease (such as chronic obstructive pulmonary disease, asthma, or pulmonary contusion), the results might be different.

To the best of our knowledge, our study is only the second study to evaluate changes in vital signs due to spinal immobilization. Although our study identified a significant decrease in SBP as a result of spinal immobilization, in the first study conducted by Bruijns et al. (21) (in which 53 healthy subjects were enrolled), the authors reported no significant change in the vital signs, including SBP. Therefore, we believe that there is a need for further studies involving a larger cohort population.

\section{Study limitations}

Our study has some limitations. First, our study involved a very small and narrow age-limited population. Therefore, our re- sults may not be enough to support precise judgments. Second, we evaluated only healthy subjects. If this study is conducted again with different patient populations such as hemorrhagic shock, hypertension diseases, or elderly patients, these results may be varied. Third, we evaluated only the effect of both LBB and $C C$; thus, it is not certain which of these caused the change in SBP levels (LBB or CC).

\section{Conclusion}

Physicians should be aware that spinal immobilization with LBB and CC can cause significant changes in some vital signs, such as SBP and VAS. However, data on this topic are limited; therefore, there is a need for further studies involving a larger cohort population.

Ethics Committee Approval: Ethics committee approval was received for this study from the ethics committee of Keçiören Training and Research Hospital (B.10.4.ISM.4.06.68.49).

Informed Consent: Written informed consent was obtained from volunteers who participated in this study.

Peer-review: Externally peer-reviewed.

Conflict of Interest: No conflict of interest was declared by the authors.

Financial Disclosure: The authors declared that this study has received no financial support.

\section{References}

1. Patton GC, Coffey C, Sawyer SM, Viner RM, Haller DM, Bose K, et al. Global patterns of mortality in young people: systematic analysis of population health data. Lancet 2009; 374: 881-92. [CrossRef]

2. ATLS Subcommittee; American College of Surgeons' Committee on Trauma; International ATLS working group. Advanced trauma life support (ATLS ${ }^{\circledast}$ ): the ninth edition. J Trauma Acute Care Surg 2013; 74: 1363-6.

3. Guly HR, Bouamra O, Little R, Dark P, Coats T, Driscoll P, et al. Testing the validity of the ATLS classification of hypovolemic shock. Resuscitation 2010; 81: 1142-7. [CrossRef]

4. Kwan I, Bunn F, Roberts I. Spinal immobilization for trauma patients. Cochrane Database Syst Rev 2001; 2: CD002803.

5. Kreinest M, Goller S, Rauch G, Frank C, Gliwitzky B, Wölfl CG, et al. Application of Cervical Collars - An Analysis of Practical Skills of Professional Emergency Medical Care Providers. PLoS One 2015; 10: e0143409.

6. Walters BC, Hadley MN, Hurlbert RJ, Aarabi B, Dhall SS, Gelb DE, et al. Guidelines for the management of acute cervical spine and spinal cord injuries: 2013 update. Neurosurgery 2013; 60: 82-1. [CrossRef]

7. National Association of EMS Physicians, American College of Surgeons Committee on Trauma. EMS spinal precautions and the used of the long backboard. Prehosp Emerg Care 2013; 17: 392-3. [CrossRef]

8. Deasy C, Cameron P. Routine application of cervical collars-what is the evidence? Injury 2011; 42: 841-2.

9. March J, Ausband S, Brown L. Changes in physical examination caused by use of spinal immobilization. Prehosp Emerg Care 2002; 6: 421-4. [CrossRef]

10. Mobbs RJ, Stoodley MA, Fuller J. Effect of cervical hard collar on intracranial pressure after head injury. ANZ J Surg 2002; 72: 389-91. [CrossRef]

11. Ham HW, Schoonhoven LL, Galer AA, Shortridge-Baggett LL. Cervical collar-related pressure ulcers in trauma patients in intensive care unit. J Trauma Nurs 2014; 21: 94-102. [CrossRef] 
12. Guly HR, Bouamra O, Spiers M, Dark P, Coats T, Lecky FE, et al. Vital signs and estimated blood loss in patients with major trauma: testing the validity of the ATLS classification of hypovolaemic shock. Resuscitation 2011; 82: 556-9. [CrossRef]

13. Kwan I, Bunn F. Effects of pre hospital spinal immobilization: a systematic review of randomized trials on healthy subjects. Prehosp Disaster Med 2005; 20: 47-53.

14. Barney RN, Cordell WH, Miller E. Pain associated with immobilization on rigid spine boards. Ann Emerg Med 1989; 18: 918.

15. Lerner EB, Billittier AJ, Moscati RM. The effects of neutral positioningwith and without padding on spinal immobilization of healthy subjects. Prehosp Emerg Care 1998; 2: 112-6. [CrossRef]

16. Cordell WH, Hollingsworth JC, Olinger ML, Stroman SJ, Nelson DR. Pain and tissue-interface pressures during spine-board immobilization. Ann Emerg Med 1995; 26: 31-6. [CrossRef]
17. Edlich RF, Mason SS, Vissers RJ, Gubler KD, Thacker JG, Pharr P, et al. Revolutionary advances in enhancing patient comfort on patients transported on a backboard. Am J Emerg Med 2011; 29: 181-6. [CrossRef]

18. Walsh M, Grant T, Mickey S. Lung function compromisedby spinal immobilization. Correspondence. Ann Emerg Med 1990; 19: 615-6. [CrossRef]

19. Totten VY, Sugarman DB. Respiratory effects of spinal immobilization. Prehosp Emerg Care 1999; 3: 347-52. [CrossRef]

20. Ay D, Aktaş C, Yeşilyurt S, Sarıkaya S, Cetin A, Ozdoğan ES. Effects of spinal immobilization devices on pulmonary function in healthy volunteer individuals. Ulus Travma Acil Cerrahi Derg 2011; 17: 103-7. [CrossRef]

21. Bruijns SR, Guly HR, Wallis LA. Effect of spinal immobilization on heart rate, blood pressure and respiratory rate. Prehosp Disaster Med 2013; 28: 210-4. [CrossRef] 